\title{
Multi-competence and first language attrition
}

Chapter · May 2016

READS

58

2 authors:

(3)

Monika Susanne Schmid

University of Essex

71 PUBLICATIONS 497 CITATIONS

SEE PROFILE
Bregtje Seton

University of Groningen

9 PUBLICATIONS 6 CITATIONS

SEE PROFILE 


\title{
Chapter 16 Multi-competence and first language attrition
}

\author{
Bregtje Seton (University of Groningen) and Monika S. Schmid (University of \\ Essex/University of Groningen)
}

\section{INTRODUCTION}

The multi-competence approach views bilingual development as a wholistic process that impacts not only on the linguistic system which is being acquired but on other languages that are already established in the mind/brain (Cook 2012). This perspective implies that the process commonly referred to as first language attrition - the changes to linguistic skills or language proficiency under conditions of reduced use - should be seen as an essential component of this wider picture. The assumption that bilingual development 'involves the whole mind of the speaker, not simply their first language (L1) or their second' (Cook 2012, p.3768) puts developments and changes which occur in the first language while another is being learned or used on an equal footing with the development of the language that is being acquired. This status of processes of change in the first language, however, is not reflected in present-day linguistic research, with investigations of and insights into L1 attrition still lagging far behind the multitude of studies of second language (L2) development.

The present contribution will give an overview of research in the field of first language attrition in a migration setting, and try to integrate those findings into the overall multicompetence framework. We would like to point out that, despite the fact that the term attrition is often perceived to imply negative connotations or collocations (cf. war of attrition), we do not use it here with any evaluative implication. On the contrary, in the same way that multi-competence approaches aim to treat $\mathrm{L} 2$ users within their own rights and deny a special status to the native speaker on the assumption that 'it is the users' own language that matters' (Cook 2012, p.1), the variety used by the attriter is not to be seen as inferior, reduced or deteriorated: it is simply a system which co-exists in the mind/brain, and thus within a larger 'language supersystem' with another (possibly dominant) language. We thus feel that, while the original label attrition may have 
been somewhat unfortunately and inappropriately chosen Endnote 1), it has become such an established term in the intervening years (with more than 5,000 hits on Google Scholar) that it would be counterproductive to change the nomenclature at this point.

The most important contribution that investigations of attrition can make to our understanding of multilingual development is that such development is neither linear nor unidirectional and that it often eludes our predictions. In other words, language users do not invariably progress in an orderly, structured and homogeneous way from a state at which they had no knowledge of a language through a series of stages, at each of which their knowledge of the language is linearly greater than it was at the previous one, converging towards (but probably never arriving at) the idealized monolingual target variety. Proficiency, complexity, accuracy, fluency, how comfortable a speaker is with the language, his or her attitudes towards it, and so on, fluctuate throughout the language user's lifespan and in all of his or her languages, and these developments are conditioned by many factors which interact in complex and often unpredictable ways.

With the growing body of research on the brain, there are potentially many insights to be gained from the perspective of neuroscience. An increase in knowledge about the brain can lead to a refinement and redefinition of the underlying models of linguistic knowledge. Thus the goal of the present chapter is to re-evaluate the existing attrition literature from a multi-competence perspective and to arrive at a more integrated picture of language attrition on the one hand and language acquisition on the other. We will conclude the survey with a brief investigation of the importance of neurophysiological models of language processing.

\section{CROSSLINGUISTIC INTERACTION AND THE QUESTION OF THE BASELINE}

Cook (2009) distinguishes different groups of L2 users, categorized according to the function which the L2 plays for them - for example, migrant communities using the L2 in their environment, speakers for whom the L2 has a limited function such as a ritualistic-religious one or a professional one, heritage speakers, and so on. These types of bilingualism have an impact 
on the characteristics of the interlanguage and the amount of bidirectional crosslinguistic interaction, but it is safe to assume that all bilinguals experience such phenomena to some extent. For approaches which focus on the way in which bilinguals use their languages as varieties in their own right, as opposed to attempting to identify deficiencies with respect to an idealized and unrealistic monolingual baseline, it is these phenomena of interaction between all of a multicompetent user's languages that are of interest.

Such an approach is of particular importance within the context of investigations that attempt to identify whether there are inherent or maturational limits to attainment in second language development. From a theoretical perspective which acknowledges the interaction of all linguistic systems known by the user, attempts to assess the performance of L2 speakers against that of monolinguals in order to identify any residual 'deficits' (such as e.g. the studies by Abrahamsson and Hyltenstam 2009; Bongaerts et al. 1997 or Hopp 2007, to name but a few) are inherently meaningless in that they may be comparing apples and oranges. It has long been known that bilingual users experience crosslinguistic traffic in all of their linguistic systems. Initially (at low levels of experience with the L2), there will be more accommodation of the L2 to the L1, but with increased experience, this status may apparently shift, and traffic in the other direction can increase. This was, for example, found in an early study by Flege (1987), who investigated phonetic production of French-American English and American English-French bilinguals. His investigation of Voice Onset Time (VOT) among these speakers revealed that all bilinguals differed from the monolingual controls in both their languages, in that their VOTs had shifted towards the values set by the other language (although the values for both languages were still clearly discriminated, i.e., the two phonetic systems had not merged or converged). In the L1, this shift was smallest for the users who had had only nine months' exposure to the L2. On the other hand, for that group of low-experience L2 users, the VOT values of the L2 were furthest away from the native production. In long-term, immersed bilinguals, crosslinguistic adaptation in the L1 increased but became reduced in the L2. 
Since this and other studies clearly indicate that the native language of a multilingual language user undergoes measurable change after only a few months' exposure to the L2 (and other studies, such as Chang (2012), have found similar effects after as little as six weeks), it seems absurd to expect any L2 user to arrive at a state where s/he will become indistinguishable from a monolingual native, or to derive theoretical explanations on the nature of second language learning from their 'failure' to do so. As Hopp and Schmid (2013) and Schmid (in press) have recently argued, more insight into the way in which language is acquired, processed and used can be gained by comparing bilinguals who use the same languages but were exposed to them in a different sequence (e.g. English-German and German-English bilinguals). Such investigations do have the potential of revealing whether the mechanisms underlying language learning do indeed change during the lifespan, what the impact is of factors such as entrenchment (reinforcement of the memory trace through repetition, i.e. a frequency effect) and competition, and how different language systems at varying levels of development interact in the human mind.

\section{PREDiCTORS OF FIRST LANGUAGE ATTRITION}

The most striking characteristic that sets bilinguals apart from monolinguals is a larger amount of variability in performance. Investigations of language attrition have often struggled to find adequate descriptive or explanatory frameworks to account for the fact that one attriter may exhibit more crosslinguistic influence than another. In early investigations it was often assumed, for example, that the process of language loss, change or reconstruction would exhibit a pattern that would be the reverse of the acquisitional process (as e.g. predicted by Jakobson (1941) in what has come to be known as the 'Regression Hypothesis') or that there would be a straightforward relationship between the amount of exposure and the degree of deterioration (the 'use it or lose it' tenet, e.g. Andersen 1982). However, more recent empirical investigations have shown that the picture is more complex and that many factors not only play a role in the process but may also interact. For example, Keijzer $(2007 ; 2010)$ finds interesting but limited 
connections between order of acquisition and attrition on some morphological features, but also demonstrates changes that can be ascribed to crosslinguistic influence which is absent in first language acquisition. Where the - apparently obvious and simplistic - prediction that lack of input and use will lead to attrition is concerned, various investigations find no clear or straightforward relation between the two (De Bot, Gommans and Rossing 1991; Köpke 1999, 2007; Schmid 2007; Schmid and Dusseldorp 2010; Schmid 2011). (Endnote 2).

Similarly, it has been shown that attrition over long periods of time is not a linear process, but that the bulk of changes to L1 accuracy and accessibility appears to take place relatively early on, probably within the first decade of emigration. The strongest evidence in this respect comes from an investigation by De Bot and Clyne (1989; 1994), who observed no (further) change in long-term emigrants at two testing moments even though these were separated by a fifteen year gap. This suggests that the key factor in the attritional process may not only be scarcity of input or use, but also that the effort devoted to acquiring another language (which is presumably highest in the first years after arrival in the new country) may play a more important role, along the line of the argument made by Herdina and Jessner (2002) that the effort to acquire a language (language acquisition effort) has an influence on the effort to maintain another already acquired language (language maintenance effort). In a similar vein, more personal factors also appear to play a role. For example, Schmid (2002; 2004) shows that emotional factors such as traumatic experiences, attitudes and identification can considerably influence the attrition process.

The only clear-cut and unambiguously important factor in determining language attrition appears to be age of arrival. Those few studies which investigate both pre- and post-puberty migrants (Ammerlaan 1996; 1997; Bylund 2009; Pelc 2001) find age at onset to be the most important predictor, while, in populations which migrated above the age of 12 , the significance of this factor disappears entirely (Köpke 1999; Schmid 2002). The most extreme instances of L1 attrition can be found among international adoptees whose L1 seems to have literally been 
'erased' from the brain (Pallier et al. 2003; Ventureyra, Pallier and Yoo 2004). In this respect, the concept of 'incomplete acquisition' is often invoked (e.g. Montrul 2008). However, as was recently pointed out (Bylund 2009; Schmid 2013), the age range of 10 to 12 appears to be an important threshold for susceptibility to reconstruction, change or deterioration for a variety of linguistic skills which are mastered at quite different stages of the acquisition process, such as nativeness in pronunciation (Yeni-Komshian, Flege and Liu 2000), case marking (Schmitt 2010), tense, mood and aspect (Silva-Corvalán 1994), lexical naming (Ammerlaan 1996) or global proficiency (Hakuta and D'Andrea 1992).

Assessing the impact of the factors listed above which act as predictors in the language attrition process is furthermore complicated by the fact that many of them may interact in complex and non-linear ways. For example, the factors of Length of Residence (LoR) and Age of Emigration (AoE) are often correlated (as e.g. in Ammerlaan 1996), since the longer the participants have been living in the host country, the younger they usually were when they emigrated. Hence, length of residence cannot always be interpreted independently of age of emigration. Nevertheless, there are studies that do find a significant effect of length of residence with late attriters, i.e. emigrants after age 17 (Jaspaert and Kroon 1989). Other studies only find a negative effect of length of residence when there is little use of the language (De Bot et al. 1991; Soesman 1997), suggesting an interaction of these factors.

The complex, non-linear interplay of predictors on the process of language attrition has recently been approached from the theoretical framework of Dynamic Systems Theory (De Bot, this volume; Opitz, de Leeuw and Lubińska 2013) which views language development as a Dynamic System in which multiple factors influence one another differently in different stages of development. It is clear that more research on large populations and sophisticated statistical modeling is needed in order to gain further insight into the role and interaction of predictor factors for attrition. 
As this short review shows, many of the factors which play a role in bilingual development in general have been addressed and investigated in the process of L1 attrition. The starting hypothesis for these investigations has usually been the assumption that what matters for L2 acquisition will play a similar role in L1 attrition. The actual data, however, have usually failed to validate such straightforward hypotheses and the question of what causes one individual language user to experience more crosslinguistic influence in their L1 than another remains unanswered. In this context it should be pointed out that the processes of acquisition and attrition are closely linked with each other, and that more insight is potentially to be gained by investigations that abandon the typical approach of studying one or the other of these developments and take a wider approach which includes the interaction of the languages and the processes of change (e.g. Schmid and Köpke 2007; Schmid, in press).

\section{NEUROPHYSIOLOGICAL EXPLANATIONS}

In order to gain more insight into the processes and factors that condition language attrition in the individual language user, it is important to take into account the neurocognition of linguistic knowledge, language use and processing, and bilingualism. Of the neurophysiological processes underpinning cognition in general and language processing and use in particular, the most straightforward concerns the role of neuronal activity and the constant rewiring of synapses depending on the activation of the neurons. The more activation there is between two neurons, the higher this amplitude of the activation between the neurons becomes and the stronger the activation will be. This goes back to the Hebbian idea of cells that fire together wiring together (Hebb 1949).

Of course, it is not simply the firing of neurons that takes place in the brain. There is, for example, a difference between excitatory and inhibitory cells that gives rise to a more complex interplay within and between different neural networks (Green 1998; Köpke 2007). Moreover, many different hormones and neurotransmitters are involved in these neural processes, and they bring about neurochemical reactions that are indispensable for the brain's functions (Lynch 
2004; Ullman 2008). The storage and consolidation of memory is assumed to happen mostly through a strengthening of synaptic connections between neurons (e.g. Squire 1985) that are activated and re-activated. Certain parts of the brain, such as the hippocampus and the amygdala, have been found to be actively involved in steering these memory formations. Additionally, sleep is thought to be an important factor in this ability to consolidate information and transfer newly acquired knowledge into long-term memory (Stickgold 2005). This is also the case for language learning, as can be deduced from studies finding better retention of language after episodes of sleep (Fenn, Nusbaum and Margoliash 2003). An in-depth review of all the neural processes involved is beyond the scope of the present chapter, all the more so since the exact processes that give rise to memory consolidation are still unclear (Lynch 2004; Stickgold 2005). We will therefore focus here on a neuronal activity-based account of the consolidation of the language. In fact, many language models, such as simple recurrent network models (Elman 2011), parallel distributed models (McClelland 2011) and other connectionist or neural network models (Seidenberg 1997), are based on this simplified notion of neural activation.

On this view of neuronal activation, every time a neuron produces electrical activity, an electrochemical trace is left along the path of the activity. If this same path is travelled again from one neuron to another, this event will be facilitated. If, on the other hand, there is no recurrence then the trace will fade. Through this process of entrenchment, the access to certain items becomes easier as they are called upon more frequently. Entrenchment has often been invoked in the context of the formation of cognitive routines (e.g. Langacker 2000; 2002), a process whereby certain functions become more and more automatized and entrenched through consecutive use.

Of course, a lack of entrenchment in the first language could very well explain why attriters with early ages of emigration show more signs of attrition, and why AoE does not appear to play such a large role at later ages of emigration. In a way, entrenchment is confounded with AoE and these two factors are then difficult to tease apart. For the acquisition of an L2 however, this idea of entrenchment does not explain why it is often found to be easier to learn 
an L2 at earlier ages as opposed to later on. A solid neurophysiological explanation for this is still lacking, but so far the strongest indicator seems to be synaptic over-production during the initial stages of development of the human brain. Different cortices have different peaks in the number of synapses available, ranging from the age of 4 to the age of 20 (Neville and Bavelier 2002). During this over-production of synapses, the extensive growth and elimination of axons and dendrites, and the forming and breaking of the connections between pre- and postsynaptic neurons leads to the development and stabilization of neural circuits (Knudsen 2004). A significant reduction of synapses plus an increase in stabilized synapses may be contributing to the critical or sensitive period that is often referred to in general learning, as well as - for our purposes - in L2 acquisition research. Nevertheless, the ongoing rearrangement of synapses after this period does still allow for a certain sensitivity to change and can therefore explain why it is possible for learning to take place at later ages and why second language learners can sometimes be very successful and native-like in their second language (Bavelier and Neville 2002; Perani and Abutalebi 2005).

The entrenchment account is important in the context of L1 attrition: no other abstract system of knowledge is used as frequently and regularly as that of the native language in a monolingual. It has been suggested that, due to the 'over-rehearsal' of this system, a saturation point of entrenchment may eventually be reached, after which frequent reactivation is no longer necessary to prevent the memory traces from fading, and that this may explain the lack of evidence found in support of the 'use it or lose it' tenet for L1 attrition (Schmid 2007). On the other hand, as the speaker becomes bilingual, memory traces will become established for the L2 which are extremely similar to those of the L1, and as proficiency and frequency of use of that language increase, it will become a formidable competitor. In some cases, the stronger L2 connections will inadvertently serve the speaker with L2 items, structures or sounds before the L1 can be activated. In this manner competition from the L2 may slow down or prevent access to the L1. Such a picture suggests that crosslinguistic interference and/or problems of 
accessibility in L1 attrition are not so much linked to actual 'language loss' (as would be the case if the memory traces had indeed eroded) as to the difficulty in accessing them, since this activation requires considerable inhibitory effort (Hulsen 2000; Köpke 1999). Such a scenario appears likely in the context of evidence showing that comprehension is typically less affected by problems of lexical access than production, as Hulsen's (2000) study of lexical naming vs. lexical decision illustrated, that apparently 'forgotten' items are (re-)acquired faster than new ones (the 'Savings paradigm', De Bot, Martens and Stoessel 2004) and that the spoken L1 of attriting language users is characterized by an increase in disfluency markers (Schmid and Beers Fägersten 2010). A potential explanation for the production/comprehension asymmetry is that a correct item from the input can be accessed by firing neurons 'recognizing' it (top-down processing), while finding the correct item through the maze of neurons that are firing in connection to the meaning of the item (bottom-up processing) is more difficult.

On this account a more important role for the process of language attrition is attributed to competing neuronal activity in the stronger L2 than to an actual degradation of the connections which represent the L1. In other words, crosslinguistic interference and problems of accessibility in the attriting language are due to a lack of inhibitory mechanisms as opposed to an insurmountable rise of the Activation Threshold (Levy et al. 2007; Linck, Kroll and Sunderman 2009). Evidence in support of this view comes from the fact that the only predictor linked with language use which has been shown to be consistently important in preventing attrition phenomena is the use of the L1 for professional purposes (Schmid 2007; Schmid and Dusseldorp 2010). In such (formal) contexts, code-switching and code-mixing is usually not considered appropriate - as opposed to the informal interactions with family members and friends in the country of migration which are usually assessed and quantified in attrition studies. Schmid (2007) thus hypothesizes that speakers who regularly use their L1 in the professional domain have more practice at resisting any intrusion from their highly active L2 and concludes 
that L1 attrition phenomena are predominantly a matter of the efficiency of processes linked to inhibition as opposed to activation problems.

Such an account may also go some way towards explaining the phenomenon of 'language reversion' that is sometimes reported by ageing migrant populations. An early account of this phenomenon is presented by Clyne (1977) and De Bot and Clyne (1989), who find that a number of their participants reported that, as they grew older, their L2 skills appeared to deteriorate and the L1 was reasserting itself. This account, however, was based solely on anecdotal evidence and has never been substantiated in empirical research. Clyne himself refers to reversion as a 'myth' later on (Clyne 2011). In this context, it is important to note that one of the most prevalent changes in cognitive ability that has been linked with the normal ageing process is an attenuation of inhibitory processes (Burke 1997; Burke and Osborne 2007; Burke and Shafto 2008; Radvansky, Zacks and Hasher 2005). It may be that the deterioration of inhibitory efficiency among older attriters can lead to more extensive code-switching and codemixing in both languages, but that, so far, they were mainly used to experiencing this in the L1. Such an unexpected intrusion of L1 elements or items in the L2 may then be interpreted in the context of the strong and widespread language reversion myth: Clyne (2011) reports that virtually all elderly migrants that he spoke to confidently expect this to happen to them at some point in the future (refreshingly, he cites an 85-year old who says that she knows she will lose her L2 and revert to her L1 'when I grow old' (p.215).

It seems clear, therefore, that investigations of L1 attrition which take into account neurophysiological processes may not only be able to find explanations for some of the puzzling and unexpected phenomena which have often been encountered in previous investigations of attrition, but to shed more light on bilingual development in general. The assumption that effects of the second language on the first are due mainly to a lack of inhibitory control, and not so much to a degradation of the memory traces underpinning the L1, is, of course, very compatible with multi-competence approaches: as languages come to co-exist within the same mind/brain, 
they will interact with each other, and where such interaction is not desired, the language that the user does not wish to select has to be inhibited. This inhibition process becomes more and more effortful the more deeply entrenched the linguistic system in question has become, and that is what leads to the process that is commonly (but misleadingly) labelled as first language attrition.

\section{NEUROCOGNITIVE APPROACHES TO LANGUAGE ATTRITION}

As was pointed out above, what little we know to date about the neurophysiological processes underpinning the language attrition process is derived from general investigations of the brain and/or language processing, not from studies focussing specifically on language attrition.

Bilingualism research to date overwhelmingly favours investigations of the second, the laterlearned or the weaker language and very few studies investigate changes to linguistic systems already established at the onset of L2 learning. This is even more true for investigations of the neurocognitive underpinnings of bilingualism: There is a large body of neuroimaging research of L2 processing, while there is hardly any direct evidence concerning the effects that bilingualism has on the L1.

In this context, too, converging evidence from developments which take place in the L1 in situations of intense bilingual use and exposure may help us gain a deeper understanding of language acquisition and processing. For example, while it is commonly accepted that L1 and L2 processing rely on the same neural mechanisms and activate similar regions in the brain, the distribution of activation in L2 speakers is also affected by factors such as proficiency levels, age at learning and amount of exposure (Perani et al. 2003; Perani and Abutalebi 2005). For the native language, these factors are generally assumed to be constant because monolingualism is considered the default. Moreover, there are no studies investigating if the neural underpinnings of (first) language processing may change when the individual speaker becomes bilingual. In other words, there may be changes in brain activation patterns when extensive bilingualism leads to a decrease in overall L1 proficiency or a dramatic reduction in L1 exposure and use. 
Similarly, investigations using other neuroimaging methods, such as Event-Related Potentials (ERPs) and eye tracking, may help elucidate to what extent bilinguals rely on different and differential features of the language. There is evidence from studies using ERPs, for example, that as L2 learners become more proficient, their processing strategies change to some extent: in low-proficiency learners, one sometimes finds brain responses that are more typical for efforts associated with semantic integration (the N400 component) when processing violations associated with grammatical features such as gender concord (Osterhout et al. 2004). Higher proficiency learners, on the other hand, tend to exhibit the P600 (Endnote 3) typically also found among native speakers when they encounter such structures, although this response is often somewhat delayed. Such findings are in line with proposals that assume that language learners, particularly when they are not yet very experienced, use lexical cues more than native speakers do, who have fully automatized their grammatical processing system (e.g. the 'Shallow Structure Hypothesis', Clahsen and Felser 2006). It would be very interesting to see what happens to longterm attriters in this type of paradigm. One possible scenario might be that, as automatized processing slows down or fails due to extended non-use, the speaker may fall back on declarative representations (this intriguing possibility was suggested by Osterhout 2014 for second language attrition). On the other hand, it is possible that automatic processing is preserved better in language attrition than declarative representations, but that it may become somewhat delayed or less efficient.

None of these questions have been systematically addressed by research on the neurocognitive aspects of bilingualism. Investigations into the neurocognition of the first language in long-term immersed bilinguals may help us gain a deeper understanding of multilingual language processing which can also shed light on questions of second language learning, as it can improve our understanding of how crosslinguistic interaction affects language processing in native speakers. This makes it possible to control for the 'bilingualism factor', as opposed to the more common comparisons of bilingual apples and monolingual oranges. 


\section{CONCLUSION}

Any investigation of bilingual development which takes seriously the proposal of multi-

competence, that is, a model of linguistic knowledge where all languages co-exist within a larger supersystem and affect each other, can be considered incomplete if it merely looks at such changes in languages that are learned later in life. For simultaneous and early bilinguals, it is already often the case that both languages are investigated, but where late bilinguals are concerned, the native language has, so far, been largely neglected. On the other hand, very few studies which do investigate L1 attrition are also interested in what is happening with the L2. We suggest that such integrated approaches are needed in order to move forward our understanding of bilingual development. In addition, a perspective which takes into account not only linguistic behaviour but also its neurocognitive underpinnings may shed more light on the puzzling phenomena that we are observing thus far.

\section{REFERENCES}

Abrahamsson, N. and Hyltenstam, K. 2009. 'Age of onset and nativelikeness in a second language: listener perception versus linguistic scrutiny', Language Learning 59(2), 249-306.

Ammerlaan, T. 1996. “'You get a bit wobbly...”: exploring bilingual lexical retrieval processes in the context of first language attrition', Unpublished doctoral dissertation, Katholieke Universiteit Nijmegen.

Ammerlaan, T. 1997. “Corrosion" or "Loss" of immigrant Dutch in Australia: an experiment on first language attrition', in J. Klatter-Folmer and S. Kroon (eds.), Dutch Overseas: Studies in Maintenance and Loss of Dutch as an Immigrant Language, Tilburg University Press, 69-97

Andersen, R.W. 1982. 'Determining the linguistic attributes of language attrition', in R. Lambert and B. Freed (eds.), The Loss of Language Skills, Rowley, MA: Newbury House, 83-118

Bavelier, D. and Neville, H. 2002. 'Cross-modal plasticity: where and how?', Nature Reviews

Neuroscience 3, 443-452 
Bongaerts, T., Van Summeren, C., Planken, B. and Schils, E. 1997. 'Age and ultimate attainment in the pronunciation of a foreign language', Studies in Second Language Acquisition 19, 44765.

Brouwer, H., Fitz, H. and Hoeks, J. 2012. 'Getting real about semantic illusions: rethinking the functional role of the P600 in language comprehension', Brain Research 1446, 127-143.

Burke, D. 1997. 'Language, aging, and inhibitory deficits: evaluation of a theory', Journals of Gerontology, Series B: Psychological Sciences and Social Sciences 52(6), 254-64.

Burke, D. and Osborne, G. 2007. 'Aging and inhibition deficits: where are the effects?', in D.S. Gorfein and C.M. MacLeod (eds.), On the Place of Inbibitory Processes in Cognition, 63-183. Washington, DC: American Psychological Association Press.

Burke, D. and Shafto, M.A. 2008. 'Language and aging', in F.I.M. Craik and T.A. Salthouse (eds.), The Handbook of Aging and Cognition, New York: Psychology Press, 373-443.

Bylund, E. 2009. 'Maturational constraints and first language attrition', Language Learning 59(3), $687-715$.

Chang, C.B. 2012. 'Rapid and multifaceted effects of second-language learning on first-language speech production', Journal of Phonetics 40(2), 249-68.

Clahsen, H. and Felser, C. 2006. 'Grammatical processing in language learners', Applied Psycholinguistics 27, 3-42.

Clyne, M. 1977. 'Bilingualism in the elderly', Talanya, 4, 45-56.

Clyne, M. 2011. 'Bilingualism, code-switching and aging: a myth of attrition and a tale of collaboration', in M.S. Schmid and W.M. Lowie (eds). Modeling Bilingualism: from Structure to Chaos, Amsterdam/Philadelphia: John Benjamins, 201-220.

Cook, V.J. 2009. 'Language user groups and language teaching', in V.J. Cook and L. Wei (eds.), Contemporary Applied Linguistics, Volume 1: Language Teaching and Learning, London, England: Continuum, 54-74. 
Cook, V.J. 2012. 'Multi-competence', in C.A. Chapelle (ed.), The Encyclopedia of Applied Linguistics. Oxford: Blackwell, 3768-3774

De Bot, K. and Clyne, M. 1989. 'Language reversion revisited', Studies in Second Language Acquisition 11, 167-77.

De Bot, K. and Clyne, M. 1994. 'A 16 year longitudinal study of language attrition in Dutch immigrants in Australia', Journal of Multilingual and Multicultural Development 15(1), 17-28.

De Bot, K., Gommans, P. and Rossing, C. 1991. 'L1 loss in an L2 environment: Dutch immigrants in France', in H.W. Seliger and R.M. Vago (eds.), First Language Attrition, Cambridge University Press, 87-98.

De Bot, K., Martens, V. and Stoessel, S. 2004. "Finding residual lexical knowledge: the "savings" approach to testing vocabulary', International Journal of Bilingualism 8(3), 373-82.

Elman, J. L. 2011. 'Lexical knowledge without a lexicon?', The Mental Lexicon 6(1), 1-33.

Fenn, K.M., Nusbaum, H.C. and Margoliash, D. 2003. 'Consolidation during sleep of perceptual learning of spoken language', Nature 425, 614-16.

Flege, J.E. 1987. 'The production of new and similar phones in a foreign language: evidence for the effect of equivalence classification', Journal of Phonetics 15, 47-65.

Friedrich, P. 1970. 'Dialectal variation in Tarascan phonology', International Journal of American Linguistics 37(3), 164-87.

Green, D.W. 1998. 'Schemas, tags and inhibition', Bilingualism: Language and Cognition 1(2), 100-4.

Hakuta, K. and D'Andrea, D. 1992. 'Some properties of bilingual maintenance and loss in Mexican background high-school students', Applied Linguistics 13(1), 72-99.

Hebb, D. O. 1949. The Organization of Behavior: a Neurophysiological Approach. New York: John Wiley.

Herdina, P. and Jessner, U. 2002. A Dynamic Model of Multilingualism: Perspectives of Change in Psycholinguistics. Clevedon: Multilingual Matters. 
Hopp, H. 2007. 'Ultimate Attainment at the Interfaces in Second Language Acquisition:

Grammar and processing', doctoral dissertation, University of Groningen.

Hopp, H. and Schmid, M.S. 2013. 'Perceived foreign accent in L1 attrition and L2 acquisition: the impact of age of acquisition and bilingualism', Applied Psycholinguistics 34(2), 361-94.

Hulsen, M. 2000. 'Language loss and language processing: three generations of Dutch migrants in New Zealand.' Unpublished doctoral dissertation, Katholieke Universiteit Nijmegen.

Jakobson, R. 1941. Kindersprache, Aphasie und allgemeine Lautgesetze. Uppsala: Almqvist and Wiksell.

Jaspaert, K. and Kroon, S. 1989. 'Social determinants of language loss', Review of Applied Linguistics (I.T.L.) 83/84, 75-98.

Keijzer, M. 2007. 'First language attrition: an investigation of Jakobson's regression hypothesis', Doctoral dissertation, Vrije Universiteit Amsterdam.

Keijzer, M. 2010. 'The regression hypothesis as a framework for first language attrition', Bilingualism: Language and Cognition 13(1), 9-18.

Knudsen, E. 2004. 'Sensitive periods in the development of the brain and behavior', Journal of Cognitive Neuroscience 16(8), 1412-25.

Köpke, B. 1999. 'L'attrition de la première language chez le bilingue tardif: Implications pour l'étude psycholinguistique du bilinguisme', Unpublished doctoral dissertation, Université de Toulouse-Le Mirail.

Köpke, B. 2007. 'Language attrition at the crossroads of brain, mind, and society', in B. Köpke, M.S. Schmid, M. Keijzer and S. Dostert (eds.), Language Attrition: Theoretical Perspectives, Amsterdam: John Benjamins, 9-37.

Köpke, B. and Schmid, M.S. 2004. 'Language attrition: the next phase', in M.S. Schmid, B. Köpke, M. Keijzer and L. Weilemar (eds.), First Language Attrition: Interdisciplinary perspectives on methodological issues, Amsterdam: John Benjamins, 1-43

Kutas, M. and Hillyard, S.A. 1980. 'Reading senseless sentences: brain potentials reflect semantic incongruity', Science 207(4427), 203-5. 
Langacker, R.W. 2000. Grammar and Conceptualization. Berlin: Mouton de Gruyter.

Langacker, R.W. 2002. Concept, Image, and Symbol: the Cognitive Basis of Grammar (2nd ed.). Berlin: Mouton de Gruyter.

Levy, B.J., Mcveigh, N.D., Marful, A. and Anderson, M.C. 2007. 'Inhibiting your native language: the role of retrieval-induced forgetting during second-language acquisition', Psychological Science 18(1), 29-34.

Linck, J.A., Kroll, J.F. and Sunderman, G. 2009. 'Losing access to the native language while immersed in a second language: evidence for the role of inhibition in second-language learning'. Psychological Science 20(12), 1507-15.

Lynch, M.A. 2004. 'Long-term potentiation and memory', Physiological Review 84, 87-136.

McClelland, J L. 2011. 'Memory as a constructive process: the parallel distributed processing approach', in S. Nalbantian, P. Matthews and J.L. McClelland (eds.), The Memory Process: Neuroscientific and Humanistic Perspectives, Cambridge, MA: MIT Press, 129-51.

Montrul, S. 2008. Incomplete Acquisition in Bilingualism. Re-examining the Age Factor. Amsterdam/ Philadelphia: John Benjamins.

Neville, H. and Bavelier, D. 2002. 'Human brain plasticity: evidence from sensory deprivation and altered language experience', in M.A. Hofman, G.J. Boer, A.J.G.D. Holtmaat, E.J.W. van Someren, J. Verhaagen and D.F. Swaab (eds.), Progress in Brain Research 138, 177-88.

Opitz, C., de Leeuw, E. and Lubińska, D. (eds.) 2013. 'Special Issue: dynamics of first language attrition across the lifespan', International Journal of Bilingualism 17(6).

Osterhout, L. 2014. 'Event-related brain potentials as metrics of non-native language learning and loss', Paper presented at the Symposium 'Second Language in the Brain', University of Greenwich, Oct. 4th 2014.

Osterhout, L., McLaughlin, J., Kim, A., Greenwald, R. and Inoue, K. 2004. 'Sentences in the brain: Event-related potentials as real-time reflections of sentence comprehension and 
language learning', in M. Carreiras and C.J. Clifton (eds.), The On-line Study of Sentence Comprehension: Eyetracking, ERP, and Beyond, New York: Psychology Press, 271-308.

Pallier, C., Dehaene, S., Poline, J.B., LeBihan, D., Mehler, J. and Dupoux, E. 2003. 'Brain imaging of language plasticity in adopted adults: can a second language replace the first?', Cerebral Cortex 13, 155-61.

Papalia, A. 1970. 'A study of attrition in foreign language enrolments in four suburban public schools', Foreign Language Annals, 4(1), 62-7.

Pelc, L. 2001. 'L1 lexical, morphological and morphosyntactic attrition in Greek-English bilinguals', Doctoral Dissertation, New York: CUNY.

Perani, D., Abutalebi, J., Paulesu, E., Brambati, S., Scifo, P., Cappa, S. F. and Fazio, F. 2003. 'The role of age of acquisition and language usage in early, high-proficient bilinguals: an fMRI study during verbal fluency', Human Brain Mapping 19(3), 170-82.

Perani, D. and Abutalebi, J. 2005. 'The neural basis of first and second language processing', Current Opinion in Neurobiology 15(2), 202-6.

Radvansky, G.A., Zacks, R.T. and Hasher, L. 2005. 'Age and inhibition: the retrieval of situation models', The Journals of Gerontology Series B 60(5), 276-278.

Schmid, M. S. 2002. First Language Attrition, Use and Maintenance: the Case of German Jews in Anglophone Countries. Amsterdam: John Benjamins.

Schmid, M. S. 2004. 'First language attrition: the methodology revised', International Journal of Bilingualism 8(3), 239-55.

Schmid, M.S. 2007. 'The role of L1 use for L1 attrition', in B. Köpke, M.S. Schmid, M. Keijzer and S. Dostert (eds.), Language Attrition: Theoretical Perspectives, Amsterdam: John Benjamins, 135-153.

Schmid, M.S. 2011. Language Attrition. Cambridge University Press.

Schmid, M.S. 2013. 'First language attrition', Linguistic Approaches to Bilingualism 3(1), 97-116. 
$\underline{\text { Schmid, M.S. in press. 'The debate on maturational constraints in bilingual development: a }}$

perspective from first language attrition', accepted for publication in Language Acquisition.

Schmid, M.S. and Beers Fägersten, K. 2010. 'Disfluency markers in L1 attrition', Language

Learning 60(4), 753-791.

Schmid, M.S. and Dusseldorp, E. 2010. 'Quantitative analyses in a multivariate study of language attrition: the impact of extralinguistic factors', Second Language Research 26(1), 125-60.

Schmid, M.S. and Köpke, B. 2007. 'Bilingualism and attrition', in B. Köpke, M.S. Schmid, M. Keijzer and S. Dostert, (eds.), Language Attrition: Theoretical Perspectives, Amsterdam: John Benjamins, 1-8.

Schmitt, E. 2010. 'When boundaries are crossed: evaluating language attrition data from two perspectives', Bilingualism: Language and Cognition 13(1), 63-72.

Seidenberg, M.S. 1997. 'Language acquisition and use: learning and applying probabilistic constraints', Science 275, 1599-1603.

Silva-Corvalán, C. 1994. Language Contact and Change: Spanish in Los Angeles. Oxford: Clarendon Press.

Soesman, A. 1997. 'An experimental study on native language attrition in Dutch adult immigrants in Israel', in J. Klatter-Folmer and S. Kroon (eds.), Dutch Overseas: Studies in Maintenance and Loss of Dutch as an Immigrant Language, Tilburg University Press, 181-194. Squire, L.R. 1985. 'Memory: neural organization and behavior', in J.M. Brookhart and V.B. Mountcastle (eds.), Handbook of Physiology: The Nervous System V, American Physiological Society, 295-371.

Stickgold, R. 2005. 'Sleep-dependent memory consolidation', Nature 437(7063), 1272-8.

Ullman, M.T. 2008. 'The role of memory systems in disorders of language', in B. Stemmer and H.A. Whitaker (Eds.), Handbook of the Neuroscience of Language, Oxford, UK: Elsevier, 189_ 198. 
Ventureyra, V. A., Pallier, C. and Yoo, H.-Y. 2004. 'The loss of first language phonetic

perception in adopted Koreans', Journal of Neurolinguistics 17(1), 79-91.

Yeni-Komshian, G.H., Flege, J.E. and Liu, S. 2000. 'Pronunciation proficiency in the first and

second languages of Korean-English bilinguals', Bilingualism: Language and Cognition 3(2),

$\underline{131-49 .}$

\section{Endnotes}

1. Despite numerous efforts on the part of the authors and other colleagues, we have been unsuccessful in tracing down the first usage of the term 'attrition' for this kind of linguistic development. The term 'language attrition' seems to have been used for the phenomenon of language change (Friedrich 1971), as well as for language instruction dropout (Papalia 1970). It seems likely that either of these uses may have been a precursor for the term, which has been in common use since the 1980s (e.g. at the 1980 UPenn symposium 'The Loss of Language Skills', convened by Barbara Freed and Richard Lambert (cf. Köpke and Schmid 2004)).

2. All of these studies acknowledge that quantity and quality of use are among the most difficult factors to measure in any situation of bilingual development, in particular since they inevitably seem to rely on subjective self-ratings by the participants themselves. They do take all possible care to arrive at sound and reliable estimates on the basis of these self-reports, but it is, of course, possible that this input factor produces less clear results due to errors of measurement, as opposed to more straightforward personal background factors such as age or length of residence.

3. The N400 is a negative-going deflection in the ERP that is generally found to peak around 400 ms after the presentation of the stimulus. This component is found to be larger for lexical items that are less frequent, or semantically less expected or implausible (e.g. spread the bread with socks as opposed to spread the bread with butter in Kutas and Hillyard 1980). It is therefore generally associated with semantic integration, but it has recently been claimed to be a marker of lexical access instead of semantic integration (Brouwer, Fitz and Hoeks 2012). 
The P600 is a positive-going deflection around $600 \mathrm{~ms}$ after the onset of the stimulus. The onset may be somewhat earlier, and it may peak around $900 \mathrm{~ms}$, since it is quite a large component. It is generally associated with reanalysis of syntactic violations, but in the recent account of Brouwer et al (2012) it is claimed to be a marker of semantic integration 